OPEN ACCESS

Edited by:

Lucia Pacifico,

Sapienza University of Rome, Italy

Reviewed by:

Vito Cantisani,

Sapienza University of Rome, Italy

Henry Dong,

University of Pittsburgh, United States

${ }^{*}$ Correspondence:

Muhammad Yazid Jalaludin yazidj@ummc.edu.my

Specialty section:

This article was submitted to

Pediatric Endocrinology,

a section of the journal

Frontiers in Pediatrics

Received: 19 September 2019

Accepted: 11 November 2019

Published: 26 November 2019

Citation:

Ting Y-W, Wong S-W, Anuar Zaini A, Mohamed $R$ and Jalaludin MY (2019)

Metabolic Syndrome Is Associated With Advanced Liver Fibrosis Among Pediatric Patients With Non-alcoholic Fatty Liver Disease.

Front. Pediatr. 7:491.

doi: 10.3389/fped.2019.00491

\section{Metabolic Syndrome Is Associated With Advanced Liver Fibrosis Among Pediatric Patients With Non-alcoholic Fatty Liver Disease}

\author{
Yi-Wen Ting ${ }^{1}$, Sui-Weng Wong ${ }^{1}$, Azriyanti Anuar Zaini ${ }^{2}$, Rosmawati Mohamed ${ }^{3}$ and \\ Muhammad Yazid Jalaludin ${ }^{2 *}$
}

${ }^{1}$ Faculty of Medicine, University of Malaya, Kuala Lumpur, Malaysia, ${ }^{2}$ Endocrinology Unit, Department of Pediatrics, Faculty of Medicine, University of Malaya, Kuala Lumpur, Malaysia, ${ }^{3}$ Gastroenterology and Hepatology Unit, Department of Medicine, Faculty of Medicine, University of Malaya, Kuala Lumpur, Malaysia

Background: Non-alcoholic fatty liver disease (NAFLD) among children is a growing concern with potential significant outcome. This study aims to investigate the relationship between hepatic steatosis, metabolic syndrome, and liver fibrosis among children with obesity and diabetes mellitus.

Methodology: Children aged 6-18 years old were recruited from pediatric obesity and diabetes clinic in University Malaya Medical Center (UMMC) between year 2016 and 2019. Data on basic demographics, anthropometric measurements and clinical components of metabolic syndrome were collected. Transient elastography was performed with hepatic steatosis and liver fibrosis assessed by controlled attenuation parameter (CAP) and liver stiffness measurement (LSM) respectively. Mild, moderate and severe steatosis were defined as $>248,>268$, and $>280 \mathrm{~dB} / \mathrm{m}$ respectively, and LSM above $7.0 \mathrm{kPa}$ for fibrosis stage $\mathrm{F} \geq 2,8.7 \mathrm{kPa}$ for $\mathrm{F} \geq 3$, and $10.3 \mathrm{kPa}$ for $\mathrm{F} 4$ (cirrhosis).

Results: A total of 57 children $(60 \%$ male) with median age of 13 years old were recruited. Fifty $(87.7 \%)$ of the children are obese and 27 (54\%) out of 50 are morbidly obese. Among 44 (77.2\%) patients with steatosis, 40 (70.2\%) had severe steatosis and 18 (40.9\%) had developed liver fibrosis of stage 2 and above. Advanced fibrosis or cirrhosis was detected in $8(18.2 \%)$ children with presence of steatosis. Twenty-three out of 57 (40.4\%) was diagnosed with metabolic syndrome. Fibrosis is three times more likely to occur in the presence of metabolic syndrome $(\mathrm{OR}=3.545,95 \% \mathrm{Cl}$ : $1.135-11.075, p=0.026$ ). Waist circumference is a significant predictor of fibrosis after multiple regression analysis.

Conclusion: Obese children with metabolic syndrome are more likely to have advanced liver fibrosis compared to those without metabolic syndrome. Waist circumference predicts development of liver fibrosis.

Keywords: NAFLD, liver fibrosis, obesity, waist circumference, insulin resistance, transient elastography 


\section{INTRODUCTION}

Non-alcoholic fatty liver disease (NAFLD) among pediatric population is increasing globally, and is currently one of the most common causes of chronic liver disease among young people in the developed world (1). According to a recent meta-analysis, prevalence of NAFLD in children from general population studies is reported to be around $7.6 \%$ and $34.2 \%$ in studies based on children's obesity clinics (2). NAFLD represents a spectrum that ranges from having fat alone without any inflammation or any evidence of liver cell injury (hepatocyte ballooning), referred to as steatosis or non-alcoholic fatty liver (NAFL), to non-alcoholic steatohepatitis (NASH), which is characterized by fat infiltration in the liver, lobular inflammation, and evidence of hepatocyte ballooning. NAFL is not benign as previously thought, with the possibility of progression to NASH, leading to fibrosis and ultimately liver cirrhosis and hepatocellular carcinoma (HCC) (3).

Metabolic syndrome describes a constellation of cardiovascular risk factors such as central adiposity, impaired glucose metabolism, hypertension, and dyslipidemia. Obesity and metabolic syndrome are closely related to NAFLD, predisposing patients to increased risk of cardiovascular events, other malignancies and mortality (4). In a 39 years follow-up study involving 44,248 male adolescents, overweight in late adolescence is found to be a significant predictor of severe liver disease later in life (5). Therefore, it is imperative to stratify patients according to their future risk of adverse outcomes, to allow for more targeted treatment strategies.

The advent of non-invasive methods such as transient elastography (TE) (Fibroscan, Paris) to detect hepatic steatosis and liver fibrosis has brought better understanding to the entity of NAFLD, particularly among adults. TE reliability and consistency on the assessment of liver fibrosis compared to gold standard liver biopsy has been proven in adult population $(6,7)$. Currently, there is no consensus in usage of TE among pediatric population, with several studies showing TE is accurate in identifying hepatic steatosis and fibrosis compared to other non-invasive assessments such as ultrasound (8-10). Although liver biopsy remains the reference standard for assessment of the degree of steatosis, its invasiveness, cost, and risk of complications are less tolerable in children and adolescents than in adults (11). Therefore, utilizing this non-invasive reproducible method of assessment, particularly among high risk groups, allows better screening of NAFLD in children.

In this study, we aim to investigate the relationship between hepatic steatosis, biochemical parameters of liver profile and components of the metabolic syndrome with severity of liver fibrosis among children with obesity and diabetes mellitus.

\section{METHODS}

\section{Study Population}

We conducted a cross-sectional study involving 57 consecutive children with age range of 6-18 years old from pediatric obesity and diabetes clinic in University Malaya Medical Center (UMMC) from 2016 to 2019. These children underwent liver stiffness measurement (LSM) and controlled attenuation parameter (CAP) using transient elastography (FibroScan, Echosens, Paris). Written informed consent was obtained from parent/legal guardian of children under 18 years of age, 18 years old adolescent provided their own consent. Participants with viral hepatitis A, B, or C infection, autoimmune hepatitis, history of alcohol intake, drug-induced fatty liver, genetic disorders, or any other causes of chronic liver diseases were excluded from the study.

\section{Clinical and Laboratory Variables}

Demographic data such as age, gender, and ethnicity were included. Anthropometric measurements including body weight, height and waist circumference (WC), and blood pressure (BP) were measured and recorded using standard equipment. BMI was calculated according to the following formula: $\mathrm{BMI}=$ weight in $\mathrm{kg} / \mathrm{height}$ in meters ${ }^{2}$. BMI-for-age percentile was calculated using World Health Organization (WHO) growth chart and was classified according to the following; $>+1$ standard deviation (SD) as overweight, $>+2 \mathrm{SD}$ as obesity, and $>+3 \mathrm{SD}$ as morbid obesity (12).

Laboratory variables such as liver function test and biochemistry profile [alanine aminotransferase (ALT), aspartate aminotransferase (AST)], gamma-glutamyl transferase [GGT] and baseline platelet count were collected at the time point of NAFLD diagnosis. ALT $>25$ IU/L was considered abnormal in boys and $>22 \mathrm{IU} / \mathrm{L}$ in girls (13). Other metabolic components such as history of diabetes mellitus status, fasting blood glucose, hemoglobin Alc ( $\mathrm{HbAlc}$ ), fasting serum insulin, history of hypertension status, systolic and diastolic blood pressure, history of dyslipidemia status, and lipid profile [total cholesterol (TC), serum triglycerides (TG) level, serum high-density lipoprotein (HDL) cholesterol level, serum low-density lipoprotein (LDL) cholesterol level] were also collected. Homeostatic Model Assessment for Insulin Resistance (HOMA-IR) model was used to quantify insulin resistance with the formula: [fasting plasma glucose $(\mathrm{mmol} / \mathrm{l}) \times$ fasting serum insulin $(\mathrm{mU} / \mathrm{l})] / 22.5$ $(14,15)$. High HOMA-IR value imply low insulin sensitivity and vice versa (14). HOMA-IR value of $>4.0$ indicates insulin resistance (16-18).

Metabolic syndrome was defined using the International Diabetes Federation (IDF) criteria with presence of abdominal obesity (WC $\geq 90$ th percentile) and 2 or more of the following criteria: serum triglyceride (TG) level $\geq 1.7 \mathrm{mmol} / \mathrm{L}$, serum HDL-cholesterol $<1.03 \mathrm{mmol} / \mathrm{L}$, systolic blood pressure (SBP) of $\geq 130 \mathrm{mmHg}$ or diastolic blood pressure (DBP) of $\geq 85 \mathrm{mmHg}$ and fasting blood glucose (FBG) $\geq 5.6 \mathrm{mmol} / \mathrm{L}$ or known type 2 diabetes mellitus (T2DM) (19). Children younger than 10 years old who fulfilled the above criteria, are considered as at risk of metabolic syndrome (19).

\section{Non-invasive Assessment of Steatosis and Fibrosis}

Transient elastography (TE) (FibroScan, Echosens, Paris) was performed by a dedicated and specially trained personnel using the $3.5-\mathrm{MHz} \mathrm{M}$ probe to obtain CAP and LSM score. We stratified patients according to the cut-offs for CAP scores as 
$\leq 248 \mathrm{~dB} / \mathrm{m}$ (normal), $249-268 \mathrm{~dB} / \mathrm{m}$ (mild steatosis), 269-280 $\mathrm{dB} / \mathrm{m}$ (moderate steatosis), and $>280 \mathrm{~dB} / \mathrm{m}$ (severe steatosis) (8). Moreover, we considered the cut-offs for LSM score as $<7.0 \mathrm{kPA}$ (F0-1, no significant fibrosis), 7.0-8.6 kPa ( $\mathrm{F} \geq 2$, mild fibrosis), 8.7-10.2 $\mathrm{kPa}$ ( $\mathrm{F} \geq 3$, moderate fibrosis), and $\geq 10.3 \mathrm{kPa}$ (F4, cirrhosis) (9).

The Pediatric NAFLD Fibrosis Score (PNFS) was calculated using serum ALT, ALP, GGT levels, and platelet counts (20). The following formula was used: $\mathrm{z}=1.1+(0.34 * \mathrm{SQRT}(\mathrm{ALT}))$ $+\left(0.002^{*} \mathrm{ALP}\right)-\left(1.1^{*} \log\right.$ (platelets) - $\left.\left(0.02^{*} \mathrm{GGT}\right)\right)(20)$. A probability distribution (p) with a value between 0 and 100 was then calculated by the following formula: $p=100 \times \exp (\mathrm{z}) /[1+$ $\exp (\mathrm{z})](20)$.

\section{Statistical Analysis}

We calculated our sample size based on difference in means of CAP and LSM between obese children and non-obese children. The effect size (Cohen d) for CAP and LSM is 2.06 and 0.92, respectively, giving a sample size of 16 and 32, respectively. Our study recruited 57 patients in anticipation of drop-out.

Data analysis were carried out using SPSS version 23.0 (Chicago, IL, USA). Values were presented as mean \pm standard deviation or median and interquartile range (IQR) for continuous variables while categorical variables were recorded as number and percentages. All variables were tested for normality using Kolmogorov-Smirnov test. Student's $t$-test was used for normally distributed variables whereas Mann-Whitney $U$-test was used for skewed variables. Correlations were assessed using Spearman's correlation coefficient. Univariate and multivariate analyses were performed to identify factors associated with progression of liver fibrosis. Receiver operating characteristic (ROC) curve analysis was used to identify the cut-off value of the PNFS with the highest sensitivity and specificity. A two-tailed $p$-value significance level of 0.05 was used for all test performed.

\section{RESULTS}

The demographic data and clinical characteristics of all subjects are summarized in Table 1. Among 57 subjects, 34 (60\%) were males and $23(40 \%)$ were females. More than half of our study population constitutes children of Malay ethnicity (64.9\%). The median age of the study population was 13 years old with age ranging from 6 to 18 years' old. Among 44 (77.2\%) patients with steatosis, $40(70.2 \%)$ had severe steatosis. Liver fibrosis of stage $\mathrm{F}$ $\geq 2$ was detected in 18 (40.9\%) children with hepatic steatosis, of which $10(22.7 \%)$ had fibrosis stage 2, 4 (9.1\%) had fibrosis stage 3 and $4(9.1 \%)$ children had liver cirrhosis or fibrosis stage 4 . There were 18 (31.6\%) who had diabetes mellitus (DM), 5 (8.8\%) had hypertension, and 23 (40.4\%) fulfilled the criteria for metabolic syndrome. Four out of eight of the patients with advanced liver fibrosis or cirrhosis had metabolic syndrome. According to WHO BMI-for-age percentile, $50(87.7 \%)$ of our study population are obese, of which, 27 (54\%) of them are morbidly obese.

Clinical characteristics were compared between patients with hepatic steatosis and liver fibrosis as shown in Table 2. Patients with $\mathrm{F} \geq 2$ liver fibrosis are categorized as presence of fibrosis. Our analyses showed that BMI were significantly higher in
TABLE 1 | Demographic and clinical characteristics of overweight and obese children $(n=57)$.

\begin{tabular}{|c|c|}
\hline Variable & All patients $(n=57)$ \\
\hline Gender, male (\%) & $34(59.6)$ \\
\hline \multicolumn{2}{|l|}{ Ethnicity, $n(\%)$} \\
\hline Malay & $37(64.9)$ \\
\hline Chinese & $7(12.3)$ \\
\hline Indian & $11(19.3)$ \\
\hline Others & $2(3.5)$ \\
\hline Age, years & $13(11,15)$ \\
\hline CAP score $(\mathrm{dB} / \mathrm{m})$ & $300(263,329)$ \\
\hline \multicolumn{2}{|l|}{ Severity of steatosis, $n(\%)$} \\
\hline Normal & $13(22.8)$ \\
\hline Mild & $2(3.5)$ \\
\hline Moderate & $2(3.5)$ \\
\hline Severe & $40(70.2)$ \\
\hline LSM score (kPa) & $6.3(3.9,8.1)$ \\
\hline \multicolumn{2}{|l|}{ Severity of fibrosis (overall), $n(\%)$} \\
\hline No significant fibrosis (FO-1) & $37(64.9)$ \\
\hline Mild (F2) & $10(17.5)$ \\
\hline Moderate (F3) & $5(8.8)$ \\
\hline Severe (F4) & $5(8.8)$ \\
\hline \multicolumn{2}{|l|}{$\begin{array}{l}\text { Severity of fibrosis (among patients with } \\
\text { steatosis), } n(\%)\end{array}$} \\
\hline No significant fibrosis (FO-1) & $26(59.1)$ \\
\hline Mild (F2) & $10(22.7)$ \\
\hline Moderate (F3) & $4(9.1)$ \\
\hline Severe (F4) & $4(9.1)$ \\
\hline \multicolumn{2}{|l|}{$\begin{array}{l}\text { Severity of fibrosis (among patients with } \\
\text { metabolic syndrome), } n(\%)\end{array}$} \\
\hline No significant fibrosis (FO-1) & $11(47.8)$ \\
\hline Mild (F2) & $7(30.4)$ \\
\hline Moderate (F3) & $3(13.0)$ \\
\hline Severe (F4) & $2(8.7)$ \\
\hline $\mathbf{A L T}\left(U L^{-1}\right)$ & $28.0(18.0,55.5)$ \\
\hline AST $\left(U L^{-1}\right)$ & $26.0(19.0,35.0)$ \\
\hline $\mathbf{G G T}\left(\mathrm{UL}^{-1}\right)$ & $24.0(17.0,44.0)$ \\
\hline Platelet $\left(10^{9} \mathrm{~L}^{-1}\right)$ & $344(270,381)$ \\
\hline Diabetes Mellitus (DM), $n$ (\%) & $18(31.6)$ \\
\hline Fasting blood sugar (FBS) $\left(\mathrm{mmol} \mathrm{L}^{-1}\right)$ & $4.8(4.6,5.4)$ \\
\hline HbA1c (\%) & $5.5(5.3,6.0)$ \\
\hline Fasting serum insulin (mU/L) & $24.2(17.7,35.4)$ \\
\hline HOMA-IR & $5.0(3.6,8.3)$ \\
\hline Hypertension, $n(\%)$ & $5(8.8)$ \\
\hline \multicolumn{2}{|l|}{ Blood pressure } \\
\hline Systolic (mmHg) & $118(114,125)$ \\
\hline Diastolic (mmHg) & $66(62,73)$ \\
\hline Triglyceride (TG) $\left(\mathrm{mmol} \mathrm{L}^{-1}\right)$ & $1.4(1.0,2.1)$ \\
\hline Total cholesterol $\left(\mathrm{mmol} \mathrm{L}^{-1}\right)$ & $4.6(3.9,5.0)$ \\
\hline HDL-C $\left(\mathrm{mmol} \mathrm{L}^{-1}\right)$ & $1.10(0.93,1.20)$ \\
\hline LDL-C $\left(\mathrm{mmol} \mathrm{L}^{-1}\right)$ & $2.78(2.32,3.14)$ \\
\hline TG: HDL-C ratio & $1.3(0.9,2.1)$ \\
\hline BMI $\left(\mathrm{kg} \mathrm{m}^{-2}\right)$ & $29.8(27.1,33.2)$ \\
\hline BMI category, $n(\%)$ & \\
\hline
\end{tabular}


TABLE 1 | Continued

\begin{tabular}{lc}
\hline Variable & All patients $(\boldsymbol{n}=\mathbf{5 7})$ \\
\hline Normal & $1(1.8)$ \\
Overweight & $6(10.5)$ \\
Obese & $23(40.4)$ \\
Morbid obese & $27(47.4)$ \\
Waist circumference $(\mathrm{cm})$ & $92.0(84.5,101.3)$ \\
Male & $97.0(86.6,107.1)$ \\
Female & $88.0(79.0,92.5)$ \\
Metabolic syndrome, $n(\%)$ & $23(40.4)$ \\
\hline
\end{tabular}

All data are expressed as median (interquartile range) unless specified. CAP, controlled attenuation parameter; LSM, liver stiffness measurement; ALT, alanine aminotransferase; AST, aspartate aminotransferase; GGT, gamma-glutamyl transferase; HOMA-IR, Homeostatic Model Assessment for Insulin Resistance; HDL-C, high-density lipoprotein cholesterol; LDL-C, low-density lipoprotein cholesterol; TG:HDL-C ratio, triglyceride to high-density lipoprotein cholesterol ratio; BMI, body mass index.

patients with steatosis than in patients without steatosis $(p=$ 0.003). Metabolic components such as HbA1c, SBP, serum TG levels, serum TC level, triglyceride to high density lipoprotein cholesterol (TG:HDL-C) ratio, BMI, and WC were significantly higher in patients with fibrosis $(p<0.05)$. DM and HOMA-IR were also significantly associated with fibrosis $(p<0.05)$. Fibrosis is three times more likely to occur in the presence of metabolic syndrome $(\mathrm{OR}=3.545,95 \% \mathrm{CI}: 1.135-11.075, p=0.026)$. Moreover, serum ALT, AST, and GGT levels were significantly higher in patients with steatosis and $\mathrm{F} \geq 2$ fibrosis $(p<0.05)$.

\section{Metabolic Predictors of Liver Fibrosis}

Multivariate regression analysis was performed to identify metabolic components which are independently associated with liver fibrosis (Table 3). The overall significance of the model was $p<0.001$ after adjusting for age. The only significant independent predictor of liver fibrosis is waist circumference. For every increase in $1 \mathrm{~cm}$ of waist circumference, LSM value increases by $0.1 \mathrm{kPa}$ (95\% CI: $0.036,0.168 ; p=0.003)$. TG:HDL$\mathrm{C}$ ratio, HOMA-IR, and hypertension were not independent predictors of liver fibrosis.

\section{Use of Pediatric NAFLD Fibrosis Score (PNFS)}

PNFS identified patients with fibrosis with an area under the ROC curve of 0.884 (95\% CI: 0.763, 1.00; $p<0.0001$ ) (Figure 1). A cut-off value of 76.6 and above detected the presence of fibrosis with a sensitivity of $81.8 \%$ and a specificity of $86.4 \%$ (positive predictive value (PPV) of $81.8 \%$ and negative predictive value (NPV) of $86.4 \%)$.

\section{DISCUSSION}

NAFLD is prevalent among children with diabetes or obesity in Malaysia with more than $75 \%$ developed hepatic steatosis and $41 \%$ developed liver fibrosis of stage 2 or above among those with steatosis. More worryingly, of those who had hepatic steatosis, almost half of the study population had significant or advanced fibrosis. Our prevalence of NAFLD among obese or diabetic children is notably higher compared to the estimated pooled prevalence of NAFLD in children, which is reported to be around $34.2 \%$ (95\% CI: $27.8-41.2 \%$ ) globally and 62.3\% (95\% CI: $34.9-$ 83.6\%) in Asia (2). Asians develop obesity and diabetes-related complications at a lower BMI than Western counterparts due to the higher deposition of visceral fat among Asian despite having similar BMI with whites (21-27). Although these landmark studies were carried out primarily in adults, similar observations were made in pediatric population, in which Asian children have increased body fat in comparison to White children at the same body mass index (28-31). For example, a national cross-sectional study done among primary schoolchildren in United Kingdom found that UK South Asian children have higher adiposity levels compared with white Europeans, but these differences were not well-represented by comparisons based on BMI, which systematically underestimates adiposity in South Asians because of its association with height (31). After BMI adjustments using regression model, South Asian children in England were revealed to have extremely high overweight-obesity prevalence (29). This further supports the theory that Asians may develop obesity-related complications at a lower BMI. We highlight that in our study, median BMI was $29.8 \mathrm{~kg} / \mathrm{m}^{2}$ with close to $90 \%$ being obese or morbidly obese. This could also account for the high prevalence of fatty liver detected, as prevalence of NAFLD increased considerably on average with increasing BMI category, keeping in mind that children may already develop fatty liver even at a lower BMI in view of increased adiposity (2). Moreover, even among children who had similar environmental exposure, there is inter-ethnic differences in hepatic fat accumulation with Malay predominantly affected. This has been demonstrated by local studies in multi-ethnics Malaysia $(32,33)$, in which the prevalence of NAFLD were consistently higher among the Malays compared to Indians and Chinese, and this ethnic predilection could be observed as early as young adulthood (34).

In this study, metabolic syndrome was found to be significantly associated with presence of significant or advanced liver fibrosis, consistent with previous studies $(35,36)$. Patton et al.'s study on 254 biopsy-proven NAFLD children has proven that metabolic syndrome, apart from being predictive of steatosis severity, is significantly associated with advanced liver fibrosis (35). Presence of one or more metabolic syndrome criteria was also demonstrated to augment the risk of liver fibrosis in another similar study, providing us the potential of utilizing metabolic syndrome as a prognostic indicator of severity of liver disease (36). Hence, we decided to identify the independent predictors of fibrosis among metabolic components in this study. Multiple regression further reveals that WC was the only independent predictor for liver fibrosis among metabolic components such as HOMA-IR, TG:HDL-C ratio and hypertension. Several studies in children population have shown that WC is a significant risk factor for liver fibrosis and it could predict risk of NAFLD in obese children $(37,38)$. This suggests that abdominal rather than generalized obesity has a greater contribution to liver fibrosis (38). Abdominal obesity leads to reduction of hepatic and insulin sensitivity (39), as visceral 
TABLE 2 | Comparison of demographic, clinical characteristics, and metabolic factors between children and adolescents with or without liver steatosis and with or without liver fibrosis.

\begin{tabular}{|c|c|c|c|c|c|c|}
\hline Variable & $\begin{array}{c}\text { Steatosis } \\
(n=44)\end{array}$ & $\begin{array}{l}\text { Without } \\
\text { steatosis } \\
(n=13)\end{array}$ & $P$ value & $\begin{array}{l}\text { Fibrosis } \\
(n=20)\end{array}$ & $\begin{array}{l}\text { Without fibrosis } \\
\qquad(n=37)\end{array}$ & $P$ value \\
\hline Gender, male (\%) & $26(59.1)$ & $8(61.5)$ & 0.874 & $12(60.0)$ & $22(59.5)$ & 0.968 \\
\hline Ethnicity, $n(\%)$ & & & $0.032^{*}$ & & & 0.248 \\
\hline Malay & $32(72.7)$ & $5(38.5)$ & & $15(75.0)$ & $22(59.5)$ & \\
\hline Chinese & $5(11.4)$ & $2(15.4)$ & & $3(15.0)$ & $4(10.8)$ & \\
\hline Indian & $5(11.4)$ & $6(46.2)$ & & $1(5.0)$ & $10(27.0)$ & \\
\hline Others & $2(4.5)$ & 0 & & $1(5.0)$ & $1(2.7)$ & \\
\hline Age, years & $13(11,15)$ & $13(11,15)$ & 0.632 & $14(12,16)$ & $12(10,14)$ & $0.007^{\star \star}$ \\
\hline CAP score $(\mathrm{dB} / \mathrm{m})$ & $315(293,346)$ & $200(133,229)$ & $0.0001^{\star \star \star}$ & $306(288,350)$ & $300(231,325)$ & 0.195 \\
\hline Severity of steatosis, $n(\%)$ & & & - & & & 0.387 \\
\hline Normal & - & $13(100)$ & & $2(10.0)$ & $11(29.7)$ & \\
\hline Mild & $2(4.5)$ & - & & $1(5.0)$ & $1(2.7)$ & \\
\hline Moderate & $2(4.5)$ & - & & $1(5.0)$ & $1(2.7)$ & \\
\hline Severe & $40(90.9)$ & - & & $16(80.0)$ & $24(64.9)$ & \\
\hline LSM score (kPa) & $6.6(4.1,8.4)$ & $4.7(3.6,6.5)$ & 0.156 & $8.95(7.65,11.05)$ & $4.3(3.6,6.1)$ & $0.0001^{\star \star \star}$ \\
\hline Severity of fibrosis, $n(\%)$ & & & 0.261 & & & - \\
\hline No significant fibrosis & $26(59.1)$ & $11(84.6)$ & & - & $37(100)$ & \\
\hline Mild & $10(22.7)$ & 0 & & $10(50.0)$ & - & \\
\hline Moderate & $4(9.1)$ & $1(7.7)$ & & $5(25.0)$ & - & \\
\hline Severe & $4(9.1)$ & $1(7.7)$ & & $5(25.0)$ & - & \\
\hline $\mathbf{A L T}\left(U L^{-1}\right)$ & $32.5(22.3,80.3)$ & $18.0(13.5,32.5)$ & $0.003^{\star *}$ & $73.0(38.8,101.5)$ & $23.0(15.5,32.0)$ & $<0.0001^{\star \star *}$ \\
\hline AST $\left(\mathrm{UL}^{-1}\right)$ & $28.0(22.0,39.0)$ & $18.0(15.8,22.5)$ & $0.012^{*}$ & $37.0(23.0,60.0)$ & $23.0(17.0,28.5)$ & $0.011^{*}$ \\
\hline $\mathbf{G G T}\left(U L^{-1}\right)$ & $26.0(18.3,59.3)$ & $17.0(12.5,26.0)$ & $0.007^{\star *}$ & $57.5(31.0,72.0)$ & $18.0(15.0,25.5)$ & $<0.0001^{\star \star *}$ \\
\hline Platelet $\left(10^{9} \mathrm{~L}^{-1}\right)$ & $357(302,395)$ & $275(236,333)$ & 0.059 & $314(246,368)$ & $354(281,405)$ & 0.175 \\
\hline Diabetes Mellitus (DM), $n(\%)$ & $13(29.5)$ & 5 (38.5) & 0.543 & $10(50.0)$ & $8(21.6)$ & $0.028^{\star}$ \\
\hline Fasting blood sugar (FBS) $\left(\mathrm{mmol} \mathrm{L}^{-1}\right)$ & $4.9(4.6,5.6)$ & $4.8(4.6,4.9)$ & 0.370 & $5.1(4.5,8.8)$ & $4.8(4.6,5.1)$ & 0.241 \\
\hline HbA1c (\%) & $5.5(5.2,6.0)$ & $5.4(5.1,6.3)$ & 0.696 & $5.7(5.4,7.6)$ & $5.4(5.2,5.7)$ & $0.035^{\star}$ \\
\hline Fasting serum insulin (mU/L) & $24.2(16.8,37.1)$ & $23.0(17.2,41.8)$ & 0.969 & $24.1(19.3,33.9)$ & $27.1(15.2,38.8)$ & 0.814 \\
\hline HOMA-IR & $5.1(3.8,9.1)$ & $4.5(1.9,9.3)$ & 0.404 & $7.1(5.3,13.0)$ & $4.2(3.0,6.8)$ & $0.005^{\star \star}$ \\
\hline Hypertension, $n$ (\%) & $4(9.1)$ & $1(7.7)$ & 0.876 & $1(5.0)$ & $4(10.8)$ & 0.459 \\
\hline \multicolumn{7}{|l|}{ Blood pressure } \\
\hline Systolic (mmHg) & $118(112,124)$ & $122(114,128)$ & 0.589 & $121(116,131)$ & $116(109,123)$ & $0.039^{*}$ \\
\hline Diastolic (mmHg) & $65(63,73)$ & $67(57,71)$ & 0.514 & $67(64,74)$ & $65(62,73)$ & 0.348 \\
\hline Triglyceride (TG) $\left(\mathrm{mmol} \mathrm{L}^{-1}\right)$ & $1.5(1.0,2.2)$ & $1.3(0.85,1.85)$ & 0.418 & $2.05(1.1,2.3)$ & $1.3(0.8,1.7)$ & $0.005^{\star \star}$ \\
\hline Total cholesterol $\left(\mathrm{mmol} \mathrm{L}^{-1}\right)$ & $4.7(4.0,5.2)$ & $4.3(3.6,4.7)$ & 0.078 & $5.0(4.1,5.8)$ & $4.4(3.8,4.8)$ & $0.024^{\star}$ \\
\hline HDL-C $\left(\mathrm{mmol} \mathrm{L}^{-1}\right)$ & $1.1(0.9,1.2)$ & $1.13(1.04,1.16)$ & 0.524 & $1.1(0.9,1.2)$ & $1.10(0.9,1.2)$ & 0.482 \\
\hline LDL-C(mmol L-1) & $2.97(2.42,3.26)$ & $2.54(2.16,2.94)$ & 0.092 & $2.97(2.51,3.83)$ & $2.64(2.26,3.03)$ & 0.141 \\
\hline TG: HDL-C ratio & $1.3(0.9,2.2)$ & $1.1(0.9,1.7)$ & 0.318 & $1.9(1.0,2.4)$ & $1.2(0.8,1.4)$ & $0.012^{\star}$ \\
\hline BMI $\left(\mathrm{kg} \mathrm{m}^{-2}\right)$ & $30.5(27.9,34.3)$ & $26.4(22.2,29.6)$ & $0.003^{\star \star}$ & $33.5(27.9,37.8)$ & $29.5(25.6,31.9)$ & $0.009^{\star \star}$ \\
\hline BMI category, $n(\%)$ & & & $0.001^{\star *}$ & & & 0.493 \\
\hline Normal & 0 & $1(7.7)$ & & 0 & $1(2.7)$ & \\
\hline Overweight & $2(4.5)$ & $4(30.8)$ & & $2(10.0)$ & $4(10.8)$ & \\
\hline Obese & $16(36.4)$ & 7 (53.8) & & $6(30.0)$ & $17(45.9)$ & \\
\hline Morbid obese & $26(59.1)$ & $1(7.7)$ & & $12(60.0)$ & $15(40.5)$ & \\
\hline Waist circumference $(\mathrm{cm})$ & $94.5(86.0,104.5)$ & $85.8(73.0,95.4)$ & 0.059 & $99.2(91.5,114.8)$ & $89.0(83.5,97.5)$ & $0.005^{\star \star}$ \\
\hline Male & $97.5(90.5,107.1)$ & $90.3(84.6,106.9)$ & 0.191 & $106.3(97.0,116.3)$ & $91.0(84.6,98.8)$ & $0.001^{\star *}$ \\
\hline Female & $89.0(82.5,94.5)$ & $71.0(66.1,85.3)$ & $0.035^{\star}$ & $88.0(81.6,100.0)$ & $88.0(71.0,93.5)$ & 0.598 \\
\hline Metabolic syndrome, $n(\%)$ & $20(45.5)$ & $3(23.1)$ & 0.148 & $12(60.0)$ & $11(29.7)$ & $0.026^{\star}$ \\
\hline
\end{tabular}

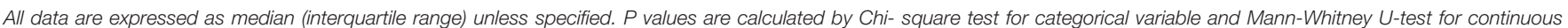



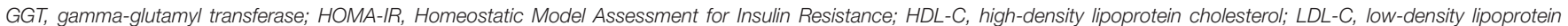
cholesterol; TG:HDL-C ratio, triglyceride to high-density lipoprotein cholesterol ratio; BMl, body mass index. Bold values represent statistically significant values. ${ }^{\star} P<0.05$, ${ }^{* *} P<0.01$, ${ }^{\star * \star} P<0.001$. 
TABLE 3 | Metabolic components independently associated with liver fibrosis (LSM value) in overweight and obese children and adolescents.

\begin{tabular}{|c|c|c|c|c|}
\hline \multirow[t]{2}{*}{ Metabolic components } & \multicolumn{4}{|c|}{ LSM value } \\
\hline & CV (95\% Cl) & $P$ value & CV (95\% Cl) & $P$ value \\
\hline Waist circumference & $0.125(0.069,0.181)$ & $0.0001^{\star \star \star}$ & $0.102(0.036,0.168)$ & $0.003^{\star \star}$ \\
\hline TG:HDL-C ratio & $-0.075(-0.982,0.832)$ & 0.868 & $0.004(-0.902,0.911)$ & 0.993 \\
\hline
\end{tabular}

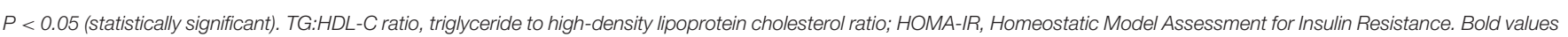
represent statistically significant values. ${ }^{* \star} P<0.01,{ }^{* \star *} P<0.001$.



FIGURE 1 | ROC of the Pediatric NAFLD Fibrosis Score (PNFS) to distinguish between NAFLD patients with and without fibrosis. The area under the ROC curve (AUROC) is 0.884 (95\% Cl: $0.763,1.00 ; p<0.0001)$.

adipose tissue is highly resistant to insulin and susceptible to lipolysis, thus producing excess free fatty acids than adipose tissue in other sites (40). The greater availability of substrate for lipogenesis, combined with the relative hyperinsulinemia effect further enhances hepatic lipogenesis, leading to a vicious cycle (41). Moreover, growing evidence suggest that obesity leads to activation of various inflammatory pathways with increased proinflammatory interleukins and cytokines activity (42-45). This supports the two-hit model theory of liver fibrosis proposed by Buzzetti et al., who suggested that the first hit consisted of fat accumulation in the liver, high fat diet, obesity, insulin resistance, and sedentary lifestyle, with the second hit consisted of activation of inflammatory process leading to fibrogenesis (46). Though WC does not accurately reflect the visceral/abdominal adiposity due to gender and ethnic differences $(47,48)$, its reliability could be improved further when combined with height or hip circumference, such as waist-circumference height ratio or waist-hip ratio (49-52). Thus, WC could be a powerful marker for NAFLD and should be utilized more frequently among obese children, as advanced non-invasive imaging such as transient elastography may not be universally available and the invasiveness of liver biopsy preclude its usage except in direst of cases. Unlike several studies which reported HOMAIR and its surrogate marker, TG:HDL-C ratio as an independent predictor of NAFLD, insulin resistance is not an independent predictor of liver fibrosis in our study (53-56). However, there is a significant association of insulin resistance and TG:HDL$\mathrm{C}$ ratio with liver fibrosis in the presence of other metabolic parameters, explaining its pivotal role in the pathogenesis of $\operatorname{NAFLD}(57,58)$.

According to a national cohort study with 39 years followup, overweight in late adolescents was a risk factor for developing severe liver disease later in life, and development of T2DM during follow-up was independently associated with a further increased risk of severe liver disease $(5,59)$. In our study, among children with metabolic syndrome, more than half of them has $\mathrm{F} \geq 2$ liver fibrosis. Intensive treatment of their underlying metabolic diseases such as lifestyle modification and tailored pharmacological management is essential to prevent further progression of liver damage, which could have disastrous consequences in future. Ideally, all pediatric patients with obesity or DM should be managed by dedicated pediatric endocrinology teams with specialist diabetes nurse, dietitian, psychologist, and sports physicians' input. However, this multidisciplinary approach may not be widely practiced, and in the case of middle-income countries, such unit would only be available in major cities with limited human resources. As such, we need to prioritize patients who needs close supervision and intensive treatment strategies.

Despite the huge burden of hepatic steatosis in children, unexpectedly we did not find any relationship between hepatic steatosis and liver fibrosis in our study. However, metabolic components such as HbAlc, HOMA-IR, SBP, serum TG level, serum TC level, TG:HDL-C ratio, BMI, and WC are significantly associated with liver fibrosis. Contrary to our study, a hospital-based study in Japan found that LSM was highly correlated with CAP among obese group (60). In spite that most of our populations were obese (87.7\%), we did not find similar correlations. Given the natural 
history of NAFLD, which has low annual incidence of fibrosis progression, we postulate that the development of fibrosis in this cohort of patient is likely contributed by the inflammatory response induced by metabolic components rather than liver steatosis itself due to relatively short exposure duration (61-64).

Multiple models have been developed to predict risk of fibrosis (20, 65-68), and we evaluated PNFS as a predictive tool for liver fibrosis. PNFS is an excellent prediction tool for liver fibrosis among children with an AUROC of 0.884, comparable with other studies with AUROC of 0.74 and 0.85 , respectively $(20,68)$. Alkhouri et al. reported that PNFS was more accurate for predicting advanced fibrosis than APRI, FIB-4 index and NAFLD fibrosis score (20). One important advantage of PNFS is utilization of values easily obtained from liver function test (ALP, ALT, GGT) and full blood count (platelet). Thus, PNFS could be use in both primary care or pediatrics setting to identify patients with probable liver fibrosis for further investigation and management.

Our study is the first study in South East Asia looking into the relationship between metabolic syndrome and liver fibrosis in diabetic or obese pediatric population by utilizing transient elastography to assess hepatic steatosis and liver fibrosis. The data were prospectively collected from a cross-sectional study, hence minimizing potential inaccuracy or incomplete data. Furthermore, our hospital-based study is conducted in a multiethnic population with similar environmental exposure. One of the limitations in our study is a relatively small population size, but adequately powered for statistical significance. In addition, liver biopsy, the gold standard for diagnosing NAFLD, was not performed in our study subjects as it is invasive with potential complication risks. MRI was not used as our imaging modality because of its high cost. Liver ultrasound elastography is suitable as non-invasive assessment tool. There are different techniques available within liver ultrasonography, such as vibration-controlled transient elastography (TE), twodimensional shear-wave elastography (2D-SWE) and point shear-wave elastography (pSWE) (69). These methods are broadly similar, but differ in terms of technical principles and sampling rate (70). Although these methods correlate with each other, specific results are not easily convertible interchangeably $(71,72)$. The major confounding factors were severe inflammation, cholestasis, liver congestion, or presence of other liver disorders $(69,70,72)$. Therefore, children with any other concomitant liver disease were excluded from our study to prevent overestimation of liver fibrosis while performing LSM with TE. Sensitivity analysis conducted as recommended by Karlas et al. and Petta et al. improve study reliability as it accounts for severity of steatosis, presence of diabetes mellitus, and body mass index $(73,74)$. Guidelines in relation to non-invasive evaluation of liver disease were developed in adult population and should be validated in children $(70,75)$. According to a meta-analysis, both TE and pSWE showed similar accuracy in staging liver fibrosis among NAFLD patients, but no direct comparisons were made (76). In contrast, a recent head-to-head comparison in NAFLD adult cohort, showed that TE was significantly better than pSWE for the diagnosis of moderate to advanced liver fibrosis (77). Meanwhile, another study comparing between TE, 2D-SWE, and pSWE in healthy children showed excellent feasibility for all methods, albeit 2D-SWE showed significantly lower LSM values than pSWE and TE, raising concern of underestimating liver fibrosis in children (78). SWE provides anatomical representation with real-time image acquisition and uses existing ultrasound $\mathrm{B}$ mode, allowing complete assessment in a single setting, thus reducing costs (79). Further studies are needed to compare the efficacy of TE and SWE in both adult and children NAFLD cohort.

In conclusion, obese children with metabolic syndrome are more likely to have advanced liver fibrosis and WC predicts risk of liver fibrosis among children with NAFLD. Hence, we advocate that waist circumference should be obtained, combining risk score such as PNFS to better select patients most at risk of advanced liver disease. As fibrosis is the most important predictor of adverse outcome in NAFLD, presence of advanced liver fibrosis at young age may increase risk of earlier onset of liver-related morbidity and mortality.

\section{DATA AVAILABILITY STATEMENT}

The datasets generated for this study are available on request to the corresponding author.

\section{ETHICS STATEMENT}

The studies involving human participants were reviewed and approved by University Malaya Medical Center (UMMC) Medical Research Ethics Committee (MREC). Written informed consent was obtained from parent/legal guardian of children under 18 years of age.

\section{AUTHOR CONTRIBUTIONS}

$\mathrm{RM}, \mathrm{AA}$, and MJ designed the research study. Y-WT, AA, and MJ established cohort and collected the clinical data for patients. Y-WT carried out data analysis and documented the findings. Y-WT and S-WW wrote the manuscript. RM, AA, MJ, and S-WW provided critical inputs to the manuscripts. All authors proof read the manuscript.

\section{ACKNOWLEDGMENTS}

The authors thank all the participants and clinical staffs of University Malaya Medical Center for the assistance with patient recruitment. We would also like to extend our gratitude toward Professor Dr. Kulenthran S/O Arumugam and Dr. Abqariyah binti Yahya@Ahmad Noor for helping out with data analysis. 


\section{REFERENCES}

1. Schwimmer JB, Deutsch R, Kahen T, Lavine JE, Stanley C, Behling C. Prevalence of fatty liver in children and adolescents. Pediatrics. (2006) 118:1388-93. doi: 10.1542/peds.2006-1212

2. Anderson EL, Howe LD, Jones HE, Higgins JP, Lawlor DA, Fraser A. The prevalence of non-alcoholic fatty liver disease in children and adolescents: a systematic review and meta-analysis. PLoS ONE. (2015) 10:e0140908. doi: 10.1371/journal.pone.0140908

3. Page JM, Harrison SA. NASH and HCC. Clin Liver Dis. (2009) 13:631-47. doi: 10.1016/j.cld.2009.07.007

4. Wong VW, Wong GL, Yip GW, Lo AO, Limquiaco J, Chu WC, et al. Coronary artery disease and cardiovascular outcomes in patients with non-alcoholic fatty liver disease. Gut. (2011) 60:1721-7. doi: 10.1136/gut.2011.242016

5. Hagstrom H, Stal P, Hultcrantz R, Hemmingsson T, Andreasson A. Overweight in late adolescence predicts development of severe liver disease later in life: a 39years follow-up study. J Hepatol. (2016) 65:363-8. doi: 10.1016/j.jhep.2016.03.019

6. Wong VW, Vergniol J, Wong GL, Foucher J, Chan HL, Le Bail B, et al. Diagnosis of fibrosis and cirrhosis using liver stiffness measurement in nonalcoholic fatty liver disease. Hepatology. (2010) 51:454-62. doi: 10.1002/hep.23312

7. European Association for the Study of the Liver, European Association for the Study of Diabetes, European Association for the Study of Obesity. EASLEASD-EASO clinical practice guidelines for the management of non-alcoholic fatty liver disease. Obes Facts. (2016) 9:65-90. doi: 10.1159/000443344

8. Ferraioli G, Calcaterra V, Lissandrin R, Guazzotti M, Maiocchi L, Tinelli $\mathrm{C}$, et al. Noninvasive assessment of liver steatosis in children: the clinical value of controlled attenuation parameter. BMC Gastroenterol. (2017) 17:61. doi: 10.1186/s12876-017-0617-6

9. Nobili V, Vizzutti F, Arena U, Abraldes JG, Marra F, Pietrobattista A, et al. Accuracy and reproducibility of transient elastography for the diagnosis of fibrosis in pediatric nonalcoholic steatohepatitis. Hepatology. (2008) 48:442-8. doi: 10.1002/hep.22376

10. de Ledinghen V, Le Bail B, Rebouissoux L, Fournier C, Foucher J, Miette $\mathrm{V}$, et al. Liver stiffness measurement in children using FibroScan: feasibility study and comparison with Fibrotest, aspartate transaminase to platelets ratio index, and liver biopsy. J Pediatr Gastroenterol Nutr. (2007) 45:443-50. doi: 10.1097/MPG.0b013e31812e56ff

11. Ratziu V, Charlotte F, Heurtier A, Gombert S, Giral P, Bruckert E, et al. Sampling variability of liver biopsy in nonalcoholic fatty liver disease. Gastroenterology. (2005) 128:1898-906. doi: 10.1053/j.gastro.2005.03.084

12. WHO. World Health Organization (WHO) BMI-for-age (5-19 years) Growth Chart 2007. Available online at: https://www.who.int/growthref/who2007_ bmi for age/en/ (accessed June 20, 2019).

13. Schwimmer JB, Dunn W, Norman GJ, Pardee PE, Middleton MS, Kerkar N, et al. SAFETY study: alanine aminotransferase cutoff values are set too high for reliable detection of pediatric chronic liver disease. Gastroenterology. (2010) 138:1357-64, 64.e1-2. doi: 10.1053/j.gastro.2009.12.052

14. Matthews DR, Hosker JP, Rudenski AS, Naylor BA, Treacher DF, Turner RC. Homeostasis model assessment: insulin resistance and beta-cell function from fasting plasma glucose and insulin concentrations in man. Diabetologia. (1985) 28:412-9. doi: 10.1007/BF00280883

15. Gungor N, Saad R, Janosky J, Arslanian S. Validation of surrogate estimates of insulin sensitivity and insulin secretion in children and adolescents. J Pediatr. (2004) 144:47-55. doi: 10.1016/j.jpeds.2003.09.045

16. Reinehr T, Andler W. Changes in the atherogenic risk factor profile according to degree of weight loss. Arch Dis Child. (2004) 89:419-22. doi: 10.1136/adc.2003.028803

17. Haffner SM, Kennedy E, Gonzalez C, Stern MP, Miettinen H. A prospective analysis of the HOMA model. The Mexico city diabetes study. Diabetes Care. (1996) 19:1138-41. doi: 10.2337/diacare.19.10.1138

18. Bonora E, Kiechl S, Willeit J, Oberhollenzer F, Egger G, Targher G, et al. Prevalence of insulin resistance in metabolic disorders: the Bruneck Study. Diabetes. (1998) 47:1643-9. doi: 10.2337/diabetes.47.10.1643

19. Federation ID. The IDF Consensus Definition of the Metabolic Syndrome in Children and Adolescents Brussels. Belgium: IDF Communications (2007). Available online at: https://www.idf.org/e-library/consensus-statements/ 61-idf-consensus-definition-of-metabolic-syndrome-in-children-andadolescents.html (accessed June 20, 2019)

20. Alkhouri N, Mansoor S, Giammaria P, Liccardo D, Lopez R, Nobili V. The development of the pediatric NAFLD fibrosis score (PNFS) to predict the presence of advanced fibrosis in children with nonalcoholic fatty liver disease. PLoS ONE. (2014) 9:e104558. doi: 10.1371/journal.pone.0104558

21. Mui P, Hill SE, Thorpe RJ Jr. Overweight and obesity differences across ethnically diverse subgroups of Asian American men. Am J Mens Health. (2018) 12:1958-65. doi: 10.1177/1557988318793259

22. Ramachandran A, Ma RC, Snehalatha C. Diabetes in Asia. Lancet. (2010) 375:408-18. doi: 10.1016/S0140-6736(09)60937-5

23. Nakagami T, Qiao Q, Carstensen B, Nhr-Hansen C, Hu G, Tuomilehto J, et al. Age, body mass index and Type 2 diabetes-associations modified by ethnicity. Diabetologia. (2003) 46:1063-70. doi: 10.1007/s00125-003-1158-9

24. Chan JC, Malik V, Jia W, Kadowaki T, Yajnik CS, Yoon KH, et al. Diabetes in Asia: epidemiology, risk factors, and pathophysiology. JAMA. (2009) 301:2129-40. doi: 10.1001/jama.2009.726

25. King GL, McNeely MJ, Thorpe LE, Mau MLM, Ko J, Liu LL, et al. Understanding and addressing unique needs of diabetes in Asian Americans, Native Hawaiians, and Pacific Islanders. Diabetes Care. (2012) 35:1181-8. doi: $10.2337 / \mathrm{dc} 12-0210$

26. Araneta MR, Barrett-Connor E. Ethnic differences in visceral adipose tissue and type 2 diabetes: Filipino, African-American, and white women. Obes Res. (2005) 13:1458-65. doi: 10.1038/oby.2005.176

27. Wang J, Thornton JC, Russell M, Burastero S, Heymsfield S, Pierson RN Jr. Asians have lower body mass index (BMI) but higher percent body fat than do whites: comparisons of anthropometric measurements. Am J Clin Nutr. (1994) 60:23-8. doi: 10.1093/ajcn/60.1.23

28. Eyre ELJ, Duncan MJ, Nevill A. South Asian children have increased body fat in comparison to white children at the same body mass index. Children. (2017) 4:102. doi: 10.3390/children4110102

29. Hudda MT, Nightingale CM, Donin AS, Owen CG, Rudnicka AR, Wells JCK, et al. Patterns of childhood body mass index (BMI), overweight and obesity in South Asian and black participants in the English National child measurement programme: effect of applying BMI adjustments standardising for ethnic differences in BMI-body fatness associations. Int J Obes. (2017) 42:662. doi: 10.1038/ijo.2017.272

30. Hudda MT, Nightingale CM, Donin AS, Owen CG, Rudnicka AR, Wells JCK, et al. Reassessing ethnic differences in mean BMI and changes between 2007 and 2013 in english children. Obesity. (2018) 26:412-9. doi: 10.1002/oby. 22091

31. Nightingale CM, Rudnicka AR, Owen CG, Cook DG, Whincup PH. Patterns of body size and adiposity among UK children of South Asian, black AfricanCaribbean and white European origin: child heart and health study in England (CHASE Study). Int J Epidemiol. (2011) 40:33-44. doi: 10.1093/ije/ dyq 180

32. Chan WK, Tan AT, Vethakkan SR, Tah PC, Vijayananthan A, Goh KL. Nonalcoholic fatty liver disease in diabetics-prevalence and predictive factors in a multiracial hospital clinic population in Malaysia. J Gastroenterol Hepatol. (2013) 28:1375-83. doi: 10.1111/jgh.12204

33. Goh SC, Ho EL, Goh KL. Prevalence and risk factors of non-alcoholic fatty liver disease in a multiracial suburban Asian population in Malaysia. Hepatol Int. (2013) 7:548-54. doi: 10.1007/s12072-012-9359-2

34. Chan WK, Bahar N, Razlan H, Vijayananthan A, Sithaneshwar P, Goh KL. Non-alcoholic fatty liver disease in a young multiracial Asian population: a worrying ethnic predilection in Malay and Indian males. Hepatol Int. (2014) 8:121-7. doi: 10.1007/s12072-013-9510-8

35. Patton HM, Yates K, Unalp-Arida A, Behling CA, Huang TT, Rosenthal P, et al. Association between metabolic syndrome and liver histology among children with nonalcoholic Fatty liver disease. Am J Gastroenterol. (2010) 105:2093-102. doi: 10.1038/ajg.2010.152

36. Manco M, Marcellini M, Devito R, Comparcola D, Sartorelli MR, Nobili $\mathrm{V}$. Metabolic syndrome and liver histology in paediatric non-alcoholic steatohepatitis. Int J Obes. (2008) 32:381-7. doi: 10.1038/sj.ijo.0803711

37. Clemente APG, Netto BDM, de Carvalho-Ferreira JP, Campos RMdS, Ganen AdP, Tock L, et al. Waist circumference as a marker for screening nonalcoholic fatty liver disease in obese adolescents. Rev Paul Pediatr. (2016) 34:47-55. doi: 10.1016/j.rppede.2015.10.004 
38. Manco M, Bedogni G, Marcellini M, Devito R, Ciampalini P, Sartorelli MR, et al. Waist circumference correlates with liver fibrosis in children with non-alcoholic steatohepatitis. Gut. (2008) 57:1283. doi: 10.1136/gut.2007. 142919

39. Marchesini G, Brizi M, Bianchi G, Tomassetti S, Bugianesi E, Lenzi M, et al. Nonalcoholic fatty liver disease: a feature of the metabolic syndrome. Diabetes. (2001) 50:1844-50. doi: 10.2337/diabetes.50.8.1844

40. Kissebah AH, Krakower GR. Regional adiposity and morbidity. Physiol Rev. (1994) 74:761-811. doi: 10.1152/physrev.1994.74.4.761

41. Haque M, Sanyal AJ. The metabolic abnormalities associated with nonalcoholic fatty liver disease. Best Pract Res Clin Gastroenterol. (2002) 16:70931. doi: 10.1053/bega.2002.0325

42. Hanauer SB. Obesity and visceral fat: a growing inflammatory disease. Nat Clin Pract Gastroenterol Hepatol. (2005) 2:245. doi: 10.1038/ncpgasthep0197

43. Fontana L, Eagon JC, Trujillo ME, Scherer PE, Klein S. Visceral fat adipokine secretion is associated with systemic inflammation in obese humans. Diabetes. (2007) 56:1010. doi: 10.2337/db06-1656

44. Nam SY, Choi IJ, Ryu KH, Park BJ, Kim YW, Kim HB, et al. The effect of abdominal visceral fat, circulating inflammatory cytokines, and leptin levels on reflux esophagitis. J Neurogastroenterol Motil. (2015) 21:247-54. doi: 10.5056/jnm 14114

45. Schlecht I, Fischer B, Behrens G, Leitzmann MF. Relations of visceral and abdominal subcutaneous adipose tissue, body mass index, and waist circumference to serum concentrations of parameters of chronic inflammation. Obes Facts. (2016) 9:144-57. doi: 10.1159/000443691

46. Buzzetti E, Pinzani M, Tsochatzis EA. The multiple-hit pathogenesis of non-alcoholic fatty liver disease (NAFLD). Metabolism. (2016) 65:1038-48. doi: 10.1016/j.metabol.2015.12.012

47. Camhi SM, Bray GA, Bouchard C, Greenway FL, Johnson WD, Newton $\mathrm{RL}$, et al. The relationship of waist circumference and BMI to visceral, subcutaneous, and total body fat: sex and race differences. Obesity. (2011) 19:402-8. doi: 10.1038/oby.2010.248

48. Grundy SM, Neeland IJ, Turer AT, Vega GL. Waist circumference as measure of abdominal fat compartments. J Obes. (2013) 2013:9. doi: $10.1155 / 2013 / 454285$

49. Lin M-S, Lin T-H, Guo S-E, Tsai M-H, Chiang M-S, Huang T-J, et al. Waistto-height ratio is a useful index for nonalcoholic fatty liver disease in children and adolescents: a secondary data analysis. BMC Public Health. (2017) 17:851. doi: 10.1186/s12889-017-4868-5

50. Prokopowicz Z, Malecka-Tendera E, Matusik P. Predictive value of adiposity level, metabolic syndrome, and insulin resistance for the risk of nonalcoholic fatty liver disease diagnosis in obese children. Can J Gastroenterol Hepatol. (2018) 2018:8. doi: 10.1155/2018/9465784

51. Gadekar T, Dudeja P, Basu I, Vashisht S, Mukherji S. Correlation of visceral body fat with waist-hip ratio, waist circumference and body mass index in healthy adults: a cross sectional study. Med J Arm Forces India. (in press). doi: 10.1016/j.mjafi.2017.12.001

52. Lindholm A, Roswall J, Alm B, Almquist-Tangen G, Bremander A, Dahlgren J, et al. Body mass index classification misses to identify children with an elevated waist-to-height ratio at 5 years of age. Pediatr Res. (2019) 85:30-5. doi: 10.1038/s41390-018-0188-4

53. Fukuda Y, Hashimoto Y, Hamaguchi M, Fukuda T, Nakamura N, Ohbora A, et al. Triglycerides to high-density lipoprotein cholesterol ratio is an independent predictor of incident fatty liver; a population-based cohort study. Liver Int. (2016) 36:713-20. doi: 10.1111/liv.12977

54. Fan N, Peng L, Xia Z, Zhang L, Song Z, Wang Y, et al. Triglycerides to high-density lipoprotein cholesterol ratio as a surrogate for nonalcoholic fatty liver disease: a cross-sectional study. Lipids Health Dis. (2019) 18:39. doi: 10.1186/s12944-019-0986-7

55. Pacifico L, Bonci E, Andreoli G, Romaggioli S, Di Miscio R, Lombardo $\mathrm{CV}$, et al. Association of serum triglyceride-to-HDL cholesterol ratio with carotid artery intima-media thickness, insulin resistance and nonalcoholic fatty liver disease in children and adolescents. Nutr Metab Cardiovasc Dis. (2014) 24:737-43. doi: 10.1016/j.numecd.2014.01.010

56. Fujii $\mathrm{H}$, Imajo $\mathrm{K}$, Yoneda $\mathrm{M}$, Nakahara $\mathrm{T}$, Hyogo $\mathrm{H}$, Takahashi $\mathrm{H}$, et al. HOMA-IR: an independent predictor of advanced liver fibrosis in nondiabetic non-alcoholic fatty liver disease. J Gastroenterol Hepatol. (2019) 34:1390-5. doi: 10.1111/jgh.14595
57. Choi SH, Ginsberg HN. Increased very low density lipoprotein (VLDL) secretion, hepatic steatosis, and insulin resistance. Trends Endocrinol Metab. (2011) 22:353-63. doi: 10.1016/j.tem.2011.04.007

58. Guo S, Copps KD, Dong X, Park S, Cheng Z, Pocai A, et al. The Irs1 branch of the insulin signaling cascade plays a dominant role in hepatic nutrient homeostasis. Mol Cell Biol. (2009) 29:5070-83. doi: 10.1128/MCB.00138-09

59. Hagstrom H, Tynelius P, Rasmussen F. High BMI in late adolescence predicts future severe liver disease and hepatocellular carcinoma: a national, population-based cohort study in 1.2 million men. Gut. (2018) 67:1536-42. doi: 10.1136/gutjnl-2016-313622

60. Cho Y, Tokuhara D, Morikawa H, Kuwae Y, Hayashi E, Hirose $\mathrm{M}$, et al. Transient elastography-based liver profiles in a hospitalbased pediatric population in Japan. PLoS ONE. (2015) 10:e0137239. doi: 10.1371/journal.pone.0137239

61. Farrell GC, Larter CZ. Nonalcoholic fatty liver disease: from steatosis to cirrhosis. Hepatology. (2006) 43(S1):S99-112. doi: 10.1002/hep.20973

62. Adams LA, Lymp JF, St. Sauver J, Sanderson SO, Lindor KD, Feldstein $\mathrm{A}$, et al. The natural history of nonalcoholic fatty liver disease: a population-based cohort study. Gastroenterology. (2005) 129:113-21. doi: 10.1053/j.gastro.2005.04.014

63. Ekstedt M, Franzén LE, Mathiesen UL, Thorelius L, Holmqvist M, Bodemar $\mathrm{G}$, et al. Long-term follow-up of patients with NAFLD and elevated liver enzymes. Hepatology. (2006) 44:865-73. doi: 10.1002/hep.21327

64. Singh S, Allen AM, Wang Z, Prokop LJ, Murad MH, Loomba R. Fibrosis progression in nonalcoholic fatty liver vs nonalcoholic steatohepatitis: a systematic review and meta-analysis of paired-biopsy studies. Clin Gastroenterol Hepatol. (2015) 13:643-54.e9. doi: 10.1016/j.cgh.2014.04.014

65. Sartorio A, Del Col A, Agosti F, Mazzilli G, Bellentani S, Tiribelli C, et al. Predictors of non-alcoholic fatty liver disease in obese children. Eur J Clin Nutr. (2007) 61:877-83. doi: 10.1038/sj.ejcn.1602588

66. Yang HR, Kim HR, Kim MJ, Ko JS, Seo JK. Noninvasive parameters and hepatic fibrosis scores in children with nonalcoholic fatty liver disease. World J Gastroenterol. (2012) 18:1525-30. doi: 10.3748/wjg.v18.i13.1525

67. Alkhouri N, Carter-Kent C, Lopez R, Rosenberg WM, Pinzani M, Bedogni G, et al. A combination of the pediatric NAFLD fibrosis index and enhanced liver fibrosis test identifies children with fibrosis. Clin Gastroenterol Hepatol. (2011) 9:150-5. doi: 10.1016/j.cgh.2010.09.015

68. Nobili V, Alisi A, Vania A, Tiribelli C, Pietrobattista A, Bedogni G. The pediatric NAFLD fibrosis index: a predictor of liver fibrosis in children with non-alcoholic fatty liver disease. BMC Med. (2009) 7:21. doi: 10.1186/1741-7015-7-21

69. Mulazzani L, Cantisani V, Piscaglia F. Different techniques for ultrasound liver elastography. J Hepatol. (2019) 70:545-7. doi: 10.1016/j.jhep.2018.10.012

70. Dietrich CF, Bamber J, Berzigotti A, Bota S, Cantisani V, Castera L, et al. EFSUMB guidelines and recommendations on the clinical use of liver ultrasound elastography, update 2017 (Long Version). Ultraschall Med. (2017) 38:e16-e47. doi: 10.1055/s-0043-103952

71. Cassinotto C, Lapuyade B, Mouries A, Hiriart JB, Vergniol J, Gaye D, et al. Non-invasive assessment of liver fibrosis with impulse elastography: comparison of Supersonic Shear Imaging with ARFI and FibroScan(R). J Hepatol. (2014) 61:550-7. doi: 10.1016/j.jhep.2014.04.044

72. Piscaglia F, Salvatore V, Mulazzani L, Cantisani V, Schiavone C. Ultrasound shear wave elastography for liver disease. a critical appraisal of the many actors on the stage. Ultraschall Med. (2016) 37:1-5. doi: 10.1055/s-0035-1567037

73. Karlas T, Petroff D, Sasso M, Fan JG, Mi YQ, de Ledinghen V, et al. Individual patient data meta-analysis of controlled attenuation parameter (CAP) technology for assessing steatosis. J Hepatol. (2017) 66:1022-30. doi: 10.1016/j.jhep.2016.12.022

74. Petta S, Maida M, Macaluso FS, Di Marco V, Camma C, Cabibi D, et al. The severity of steatosis influences liver stiffness measurement in patients with nonalcoholic fatty liver disease. Hepatology. (2015) 62:1101-10. doi: $10.1002 /$ hep. 27844

75. European Association for Study of Liver, Asociacion Latinoamericana para el Estudio del Higado. EASL-ALEH clinical practice guidelines: non-invasive tests for evaluation of liver disease severity and prognosis. J Hepatol. (2015) 63:237-64. doi: 10.1016/j.jhep.2015.04.006

76. Jiang W, Huang S, Teng H, Wang P, Wu M, Zhou X, et al. Diagnostic accuracy of point shear wave elastography and transient elastography for 
staging hepatic fibrosis in patients with non-alcoholic fatty liver disease: a meta-analysis. BMJ Open. (2018) 8:e021787. doi: 10.1136/bmjopen-2018021787

77. Leong WL, Lai LL, Nik Mustapha NR, Vijayananthan A, Rahmat K, Mahadeva $\mathrm{S}$, et al. Comparing point shear wave elastography (ElastPQ) and transient elastography for diagnosis of fibrosis stage in non-alcoholic fatty liver disease. J Gastroenterol Hepatol. (2019). doi: 10.1111/jgh.14782. [Epub ahead of print].

78. Mjelle AB, Mulabecirovic A, Havre RF, Rosendahl K, Juliusson PB, Olafsdottir E, et al. Normal liver stiffness values in children: a comparison of three different elastography methods. $J$ Pediatr Gastroenterol Nutr. (2019) 68:706-12. doi: 10.1097/MPG.00000000000 02320

79. Kanayama Y, Kamiyama N, Maruyama K, Sumino Y. Real-time ultrasound attenuation imaging of diffuse fatty liver disease. Ultrasound
Med Biol. (2013) 39:692-705. doi: 10.1016/j.ultrasmedbio.2012. 10.021

Conflict of Interest: The authors declare that the research was conducted in the absence of any commercial or financial relationships that could be construed as a potential conflict of interest.

Copyright (c) 2019 Ting, Wong, Anuar Zaini, Mohamed and Jalaludin. This is an open-access article distributed under the terms of the Creative Commons Attribution License (CC BY). The use, distribution or reproduction in other forums is permitted, provided the original author(s) and the copyright owner(s) are credited and that the original publication in this journal is cited, in accordance with accepted academic practice. No use, distribution or reproduction is permitted which does not comply with these terms. 